\title{
1 \\ 2 \\ 3 \\ Chondrogenesis and integration of mesenchymal stem cells within an in vitro cartilage defect repair model
}

\author{
Vinardell, T; Thorpe, S D; Buckley, C T; Kelly, D J \\ Trinity Centre for Bioengineering, School of Engineering, Trinity College Dublin, \\ Ireland.
}

*Corresponding author

E-mail address: kellyd9@tcd.ie

Address: Trinity Centre for Bioengineering

School of Engineering

Trinity College Dublin

Dublin 2

Ireland

Telephone: +353-1-896-3947

Fax: +353-1-679-5554 


\begin{abstract}
Integration of repair tissue is a key indicator of the long-term success of cell-based therapies for cartilage repair. The objective of this study was to compare the in vitro chondrogenic differentiation and integration of agarose hydrogels seeded with either chondrocytes or bone marrow derived mesenchymal stem cells (MSCs) in defects created in cartilage explants. Chondrocytes and MSCs were isolated from porcine donors, suspended in $2 \%$ agarose and then injected into cylindrical defects within the explants. These constructs were maintained in a chemically defined medium supplemented with $10 \mathrm{ng} / \mathrm{ml}$ of TGF- $\beta 3$. Cartilage integration was assessed by histology and mechanical push-out tests. After 6 weeks in culture, chondrocyte seeded constructs demonstrated a higher integration strength $(64.4 \pm 8.3 \mathrm{kPa})$ compared to MSC seeded constructs $(22.7 \pm 5.9 \mathrm{kPa}) . \mathrm{GAG}(1.27 \pm 0.3 \mathrm{kPa}$ vs $0.19 \pm 0.03 \mathrm{kPa})$ and collagen $(0.31 \pm 0.08 \mathrm{kPa}$ vs $0.09 \pm 0.01 \mathrm{kPa})$ accumulation in chondrocyte seeded constructs was greater than that measured in the MSC seeded group. The GAG, collagen and DNA content of both chondrocyte and MSC-seeded hydrogels cultured in cartilage explants was significantly lower than control constructs cultured in free swelling conditions. The results of this study suggest that the explant model may constitute a more rigorous in vitro test to assess MSC therapies for cartilage defect repair.
\end{abstract}

Key Terms: Push out test; Integration; Chondrogenesis; TGF- $\beta 3$; Stem cells; Chondrocytes. 


\section{Introduction}

Autologous chondrocyte implantation (ACI), ${ }^{8,44}$ and scaffold-based variants whereby cells are incorporated within supporting three dimensional (3D) scaffolds or hydrogels 2,33,49 are promising alternative strategies for articular cartilage repair. However, there are several problems associated with the ACI procedure, including difficulties in obtaining a sufficient number of chondrocytes for transplantation, the necessity of creating donor-site defects within the articular cartilage, and variability in the quality of repair. ${ }^{16}$ Mesenchymal stem cells (MSCs) possess the ability to proliferate extensively ex vivo while maintaining their multipotent differentiation capabilities, ${ }^{9,24}$ making them an attractive cell type for cell-based cartilage repair strategies. These cells can be isolated from the bone marrow using minimally invasive techniques from non-critical locations such as the iliac crest, and have the capacity to differentiate along a number of different mesenchymal lineages including bone, cartilage and fat. ${ }^{11,23,32,45}$ The chondrogenic differentiation potential of MSCs can be demonstrated in vitro using well established procedures. ${ }^{5,23}$ A major challenge with MSC based cartilage repair therapies is to generate cells with features of stable chondrocytes which are resistant to hypertrophy and terminal differentiation, as found in hyaline articular cartilage. $^{42}$

Transplantation of isolated autologous bone-marrow derived MSCs suspended in hydrogels have been shown to promote the repair of articular cartilage defects in young and/or active patients..$^{27,57}$ Successful long-term regeneration of articular cartilage defects using chondrocytes, MSCs or otherwise, requires integration of the repair tissue with the surrounding host cartilage. ${ }^{1}$ It has been demonstrated that 8 months following implantation of chondrocytes in an equine model the integration strength of the repair tissue, as measured by a uniaxial tensile test, is approximately 
half that compared to intact control samples. ${ }^{15}$ Poor integration could lead to an altered stress state within the regenerating tissue and ultimately its degeneration. In vitro explant models of cartilage defect repair have contributed significantly to our understanding of tissue integration and the ability of cell-based therapies to fill defects with articular cartilage-like repair tissue. ${ }^{20,40}$ These models allow for a systematic analysis of various factors (e.g. cells, biophysical and biochemical cues, inflammatory components etc) governing successful repair, without the natural variability found in animal models, such as the host immune response and levels of physical activity. ${ }^{20}$ Using such explant models it has been possible to demonstrate that chondrogenesis and subsequent integration of tissue engineered cartilage depends on factors such as the choice of scaffold, ${ }^{20}$ the developmental stage of the construct ${ }^{40}$ and the adjacent tissue architecture and composition. ${ }^{53}$ Integration of such tissues has been further investigated following subcutaneous implantation in nude mice..$^{22,43,50}$ These models have revealed that the tensile strengths of bonds formed between articular cartilage and engineered cartilage increase with time, with little observed differences between the quality of integrative repair using articular or non-articular chondrocytes. ${ }^{22}$

Multiple in vitro studies have demonstrated chondrogenesis of MSCs in pellet culture or on scaffolds in the presence of transforming growth factor- $\beta$ (TGF- $\beta$ ) family members. ${ }^{4,18,23,30,36,50,52,58,59}$ These studies have typically characterised chondrogenesis through the expression and synthesis of cartilage-specific matrix molecules. A number of studies have also investigated the functional mechanical properties of cartilaginous tissues engineered using MSCs, suggesting that the mechanical properties (e.g. equilibrium Young's modulus, dynamic modulus) of such constructs are lower than that produced by chondrocytes under identical conditions. ${ }^{14,36}$ What remains unclear is what effect the complex milieu of factors and 
stimuli that such constructs will experience in vivo will have on chondrogenesis of MSCs. For example, what role the surrounding articular cartilage and the associated factors released (e.g. matrix metalloproteinases, cathepsins, nitric oxide etc) will have on chondrogenesis of MSCs is poorly understood. The aim of the present study is to adapt a well established cartilage explant model that has been used to access chondrocyte-based therapies for cartilage repair to investigate MSC-based therapies. Such models, while obviously not incorporating many of the stimuli present in vivo, do recapitulate certain aspects of the environment of a cartilage defect absent in traditional pellet cultures and other in vitro systems. The specific objectives of the present study were to (i) compare the ability of chondrocytes and MSCs to form neocartilage in an in vitro cartilage explant defect model and (ii) to evaluate the mechanical integrity of the bond formed between the engineered and normal tissue using these two cell types.

\section{Materials and methods}

\section{Cell and cartilage isolation and construct assembly}

Articular cartilage was aseptically harvested from the femoropatellar joints of two immature/young pigs (four month old). Full depth articular cartilage explants were obtained using a $6 \mathrm{~mm}$ biopsy punch (Kai Medical Europe, Germany), and the height standardised to $2 \mathrm{~mm}$ through removing both the superficial and deep zones using a custom-built rig. Full depth concentric circular holes (3 $\mathrm{mm}$ diameter) were cut using a biopsy punch (Kai Medical Europe, Germany) to form annuli of tissue.

Chondrocytes and MSCs were harvested from the same donor pigs from which the cartilage explants were harvested. Chondrocytes were isolated from articular cartilage harvested from the femoropatellar joints. Briefly, cartilage slices were rinsed with 
phosphate buffered saline containing penicillin/streptomycin $(200 \mathrm{U} / \mathrm{ml})$. The cartilage chunks were then combined and digested via serial digestion with pronase $(1 \mathrm{mg} / \mathrm{ml})$ for 1 hour, then rinsed in PBS followed by incubation with DMEM/F12 containing collagenase type II $(0.5 \mathrm{mg} / \mathrm{ml})$ (all from Sigma-Aldrich, Dublin, Ireland) for $16-18$ hours under constant rotation at $37^{\circ} \mathrm{C}$. The resulting cell suspension was then filtered through a $40 \mu \mathrm{m}$ pore-size cell sieve (Falcon Ltd, Sarstedt, Ireland) and the filtrate centrifuged and rinsed with PBS twice. Cells were seeded at a density of 50,000 cells $/ \mathrm{cm}^{2}$ in $175 \mathrm{~cm}^{2} \mathrm{~T}$ flasks and expanded to passage one (P1). Viable cells were counted using a hemacytometer and $0.4 \%$ trypan blue staining. Isolated chondrocytes from all joints were pooled and maintained in DMEM/F-12 (SigmaAldrich, Dublin, Ireland) supplemented with $10 \%$ v/v foetal bovine serum (FBS) and 100U/ml penicillin/streptomycin (GIBCO, Biosciences, Dublin, Ireland) during the expansion phase. Porcine MSCs were isolated from marrow obtained from the femoral shaft, and expanded according to a modified method developed for human MSCs ${ }^{29}$. MSCs were sub-cultured at a ratio of 1:2 following colony formation and expanded to passage three.

Chondrocytes and MSCs were suspended in 2\% agarose at a density of 15 million cells/ml. The solution was aspirated with a $1 \mathrm{ml}$ warm syringe (BD, Belgium) and 18 gauge needle (BD, Microlance, Ireland) and injected into the cores created in the cartilage explants, see Fig.1. The constructs were set for 3 minutes in petri dishes to allow the agarose to cool and then they were transferred to 6 well plate dishes with culture medium ( 2 samples per well with $2.5 \mathrm{ml}$ of medium per construct, see below). Free swelling (FS) controls (no surrounding cartilage) $(n=5)$ and cartilage constructs (cartilage core in cartilage explant - histological analysis only) were also kept in similar conditions (Fig.1). All constructs were maintained for 6 weeks in a chemically 
defined chondrogenic medium (CM) consisting of DMEM GlutaMAX supplemented with penicillin $(100 \mathrm{U} / \mathrm{mL})$-streptomycin $(100 \mu \mathrm{g} / \mathrm{mL})$ (both GIBCO, Biosciences, Ireland), $100 \mu \mathrm{g} / \mathrm{ml}$ sodium pyruvate, $40 \mu \mathrm{g} / \mathrm{ml} \mathrm{L}$-proline, $50 \mu \mathrm{g} / \mathrm{ml} \mathrm{L}$-ascorbic acid-2phosphate, $1 \mathrm{mg} / \mathrm{ml}$ BSA, $1 \times$ insulin-transferrin-selenium (all from Sigma-Aldrich, Ireland) and $10 \mathrm{ng} / \mathrm{ml}$ recombinant human transforming growth factor- $\beta 3$ (TGF- $\beta 3$; R\&D Systems, UK). Medium was changed every 2-3 days. For the first 2 weeks of the experiment medium was supplemented with $100 \mathrm{nM}$ dexamethasone.

\section{MSC Tripotentiality}

\section{Adipogenesis and Osteogenesis}

MSCs were plated on $9.5 \mathrm{~cm}^{2}$ six well plates at a density of $10^{3}$ cells $/ \mathrm{cm}^{2}$ and cultured for 7 days in complete medium (DMEM GlutaMAX supplemented with 10\% v/v foetal bovine serum (FBS) and 100U/ml penicillin/streptomycin) which was then changed to osteogenic or adipogenic medium for 21 days. Osteogenic medium consisted of complete medium supplemented with $100 \mathrm{nM}$ dexamethasone, $10 \mathrm{mM} \beta$ glycerolphosphate and $0.05 \mathrm{mM}$ ascorbic acid (Sigma). Adipogenic medium consisted of complete medium supplemented with $100 \mathrm{nM}$ dexamethasone, $0.5 \mathrm{mM}$ isobutylmethylxanthine and 50 $\mu \mathrm{M}$ indomethacin (Sigma). Adipogenesis was accessed by ethanol fixing followed by staining with $1 \%$ Oil Red solution, while for osteogenic differentiation the plates were fixed with ethanol and stained with 1\% Alizarin Red solution.

\section{Chondrogenesis}

A pellet culture was used to access chondrogenesis. 250,000 cells were placed in a 1.5 $\mathrm{ml}$ conical microtube and centrifuged at $650 \mathrm{G}$ for 5 minutes. The pellets were cultured in CM. For histological evaluation the pellets were embedded in paraffin, cut 
into $5 \mathrm{~m}$ thick sections, and stained with $1 \%$ alcian blue 8GX (Sigma-Aldrich, Ireland) in $0.1 \mathrm{M} \mathrm{HCl}$ to assess glycosaminoglycan (GAG) content and picrosirius red to detect collagen.

\section{Mechanical testing}

The integration strength of the MSCs and chondrocytes seeded agarose hydrogels to the cartilage explant was evaluated at week 6 using a push out test. The engineered tissue was pushed out with a $2.5 \mathrm{~mm}$ diameter plunger, while the cartilage explant was supported on a rigid annulus ( $6 \mathrm{~mm}$ outer diameter, $3.5 \mathrm{~mm}$ inner diameter), similar to other tests reported in the literature..$^{20,40}$ The maximum force achieved before separation of the tissues (Fig. 2) was normalized by the lateral area of the core, with the resulting value considered as the failure stress, as described elsewhere ${ }^{20}$.

\section{Cell viability, histology and immunohistochemistry}

Viability of agarose encapsulated cells within explants was assessed 48 hours after encapsulation using fluorescent membrane integrity assay, LIVE/DEAD® Assay (Invitrogen, Biosciences, Ireland). Explants were incubated with $4 \mu \mathrm{M}$ calcein-AM and $2 \mu \mathrm{M}$ ethidium homodimer for 1 hour and observed using a confocal microscope (Zeiss, LSM-510-META) with a laser excitation wavelength of $490 \mathrm{~nm}$, and fluorescent emissions collected at wavelengths above $520 \mathrm{~nm}$.

Following the 6 week culture period, constructs were fixed in $4 \%$ paraformaldehyde overnight, rinsed in PBS, processed on an automated tissue processor (ASP300 Leica, Germany), embedded in wax and sectioned to $10 \mu \mathrm{m}$ thickness. The histological sections were stained with 1\% alcian blue 8GX (SigmaAldrich, Ireland) in $0.1 \mathrm{M} \mathrm{HCl}$ to assess glycosaminoglycan content and picrosirius 
red to detect collagen. Type I and type II collagen content were evaluated with a standard immunohistochemical technique. Briefly sections were treated with chondroitinase ABC (Sigma) in a humidified environment to enhance permeability of the extracellular matrix by removal of chondroitin sulphate. Slides were rinsed with PBS, quenched of peroxidase activity, and blocked with goat serum for 2 hours. Sections were then incubated overnight at $4^{\circ} \mathrm{C}$ with mouse monoclonal collagen type I diluted 1:400 (Abcam, UK) (concentration $5.4 \mathrm{mg} / \mathrm{ml}$ ) or mouse monoclonal anticollagen type II diluted 1:100 (Abcam, UK) (concentration $1 \mathrm{mg} / \mathrm{ml}$ ). After washing in PBS, the secondary antibody for type I and type II collagen (Anti-Mouse IgG Biotin antibody produced in goat) (concentration $1 \mathrm{~g} / \mathrm{L}$ ) binding was applied for 1 hour. Color was developed using the Vectastain $\mathrm{ABC}$ reagent (Vectastain $\mathrm{ABC}$ kit, Vector Laboratories, UK) for $45 \mathrm{~min}$ and $5 \mathrm{~min}$ exposure to Peroxydase DAB substrate kit (Vector laboratories, UK). Negative and positive controls were included in the immunohistochemistry staining protocol for each batch. The cartilage sections were examined with an Olympus IX51 microscope and mounted with an Olympus video camera.

\section{Biochemical analysis}

Constructs were assessed after 6 weeks of culture. Free swelling controls were cored using a $3 \mathrm{~mm}$ biopsy punch, the wet mass of both annulus and core recorded and then frozen for subsequent analyses. These cores were compared to engineered tissue formed within the cell seeded explants. For the cell seeded explants, the engineered cartilage (after push-out tests) and surrounding cartilage tissue were also weighed and frozen for separate biochemical analyses. All samples were digested in papain $(125 \mu \mathrm{g} / \mathrm{ml})$ in $0.1 \mathrm{M}$ sodium acetate, $5 \mathrm{mM}$ cysteine $\mathrm{HCl}, 0.05 \mathrm{M}$ EDTA, pH 6.0 (all 
from Sigma-Aldrich, Dublin, Ireland) at $60^{\circ} \mathrm{C}$ under constant rotation for 18 hours. Aliquots of the digest samples were assayed separately for DNA and sulfated glycosaminoglycan (GAG) content. DNA content was quantified using the Hoechst Bisbenzimide 33258 dye assay as described previously. ${ }^{26} \mathrm{~A}$ standard curve was generated with calf thymus DNA (Sigma-Aldrich, Dublin, Ireland). The proteoglycan content was estimated by quantifying the amount of sulfated glycosaminoglycan (GAG) in constructs using the dimethylmethylene blue dye-binding assay (Blyscan, Biocolor Ltd., Northern Ireland), with a chondroitin sulfate standard. Total collagen content was determined by measuring the hydroxyproline content, using a hydroxyproline-to-collagen ratio of 1:7.69. ${ }^{21,25}$ Each biochemical constituent (DNA, hydroxyproline and GAG) was normalised to the tissue wet weight.

\section{Statistical analysis}

Mechanical and biochemical properties of engineered constructs are expressed in the form of mean \pm standard deviation (SD). Five samples were made per group; 3 samples were used for mechanical and biochemical analyses and 2 samples were used for histology. Differences in mechanical and biochemical properties with cell type and culture condition were determined by using either a student t-test or two way ANOVA with Bonferroni post-tests. All calculations were performed using commercially available software (GraphPadPrism 4, San Diego, USA). A level of $\mathrm{p}<0.05$ was considered significant.

\section{Results}

Stromal cells isolated from the bone marrow of young porcine femora demonstrated the ability to differentiate down the osteogenic, adipogenic and chondrogenic lineages 
(Fig. 3). Oil droplets were observed around cells cultured with adipogenic medium after 21 days. Calcified nodules were observed in plates supplemented with osteogenic medium, while pellets stained positive for both collagen (picrosirius red) and GAG (alcian blue).

The LIVE/DEAD® Assay demonstrated dual staining (red for dead cells and green for live cells) in the cartilage and in the seeded hydrogels 48 hours after cell encapsulation, with greater cellularity observed in the cartilage explant (Fig.4). Dead cells were concentrated within the interface between the cartilage and agarose seeded gel. The interface was characterized by a thin acellular region between the cartilage and hydrogel. No obvious difference in the initial viability between MSC and chondrocyte seeded constructs was observed.

Alcian blue and picrosirius red staining revealed that chondrocytes seeded in agarose hydrogels demonstrated enhanced GAG and collagen accumulation compared to MSCs in this cartilage explant model (Fig.5). Little or no gaps were observed between the cell seeded hydrogels and the surrounding cartilage with minimal evidence of interdigitation between the two tissues for both MSC and chondrocyte groups. In comparison small gaps were observed at the interface between explants filled with cartilage plugs that had not filled with neocartilage after 6 weeks in culture (Fig.5). Immunohistochemistry demonstrated positive staining for collagen type II in both the chondrocyte and MSC groups, with weak type I staining. Staining for type II collagen was more uniform in the chondrocyte seeded group, but more localised to the cells in the MSC group. A similar trend was observed with the picrosirius red staining. The cartilage surrounding the hydrogel always stained positive for type II collagen. 
Greater GAG accumulation was measured in chondrocyte seeded constructs $(1.27 \pm 0.3 \% \mathrm{w} / \mathrm{w})$ compared to MSC seeded constructs $(0.19 \pm 0.03 \% \mathrm{w} / \mathrm{w})$ $(\mathrm{p}<0.0001)$ (Fig.6b). A similar trend was observed for collagen content, with greater accumulation in the chondrocyte group $(0.31 \pm 0.08 \% \mathrm{w} / \mathrm{w})$ compared to the MSC seeded group $(0.09 \pm 0.01 \% \mathrm{w} / \mathrm{w})(\mathrm{p}<0.05) \quad($ Fig.6c). DNA content was not significantly different for MSC and chondrocyte seeded constructs (Fig.6a). Control constructs cultured in free swelling conditions (i.e. not in cartilage explants) demonstrated higher GAG, DNA and collagen $(\mathrm{p}<0.05)$ content than those cultured in cartilage explants. For chondrocyte-seeded controls not surrounded by cartilage, GAG content was $1.7 \pm 0.1 \% \mathrm{w} / \mathrm{w}, \quad$ DNA content was $0.04 \pm 0.003 \% \mathrm{w} / \mathrm{w}$ and collagen content was $0.98 \pm 0.13 \%$ w/w. For MSC-seeded controls not surrounded by cartilage, GAG content was $0.65 \pm 0.01 \%$ w/w, DNA was $0.03 \pm 0.002 \%$ w/w and collagen content was $0.42 \pm 0.08 \% \mathrm{w} / \mathrm{w}$.

After 6 weeks in culture chondrocyte seeded constructs demonstrated a significantly higher failure stress $(64.4 \pm 8.3 \mathrm{kPa})$ during push-out testing from the surrounding cartilage explant compared to MSC seeded constructs $(22.7 \pm 5.9 \mathrm{kPa})$ $(\mathrm{p}=0.0026)$ (Fig.6d). Earlier assessment (week 3) of the integrative mechanical properties of cell seeded hydrogels could not be accurately determined because of the relatively weak integration of the gels to the cartilage explants at these time points. Biochemical analysis of engineered tissues at week 3 revealed a similar trend to that observed at week 6 (data not shown).

\section{Discussion}

Integration of native tissue and repair tissue is a key indicator of the long-term success of tissue-engineered approaches to cartilage repair. In this in vitro model of cartilage 
defect repair, it has been demonstrated that chondrocytes accumulate greater amounts of cartilaginous matrix than MSCs in the agarose gels, which is in agreement with the findings of previous studies in free swelling culture. ${ }^{36}$ Based on the results of the push-out test, cartilaginous tissue secreted by chondrocytes also integrates better with the surrounding tissue. This result may simply be a function of the higher GAG content associated with the chondrocyte seeded constructs results in greater swelling of the engineered tissue, thereby increasing the peak forces obtained from the pushout test utilised in this study. Previous studies have suggested that the failure stress of such an interface is not purely a function of the total biochemical content of the engineered tissue, ${ }^{20}$ and may depend more on the formation of cross-links between the adjacent tissues which were not measured in this study. The higher failure stress observed in chondrocyte seeded hydrogels may also be due to factors other than the strength of the bond between the adjacent tissues. It has been demonstrated that the outgrowing fibrous tissue formed during in vitro culture of cartilaginous specimens significantly increases the failure stress obtained from push-out tests. ${ }^{37}$ While pilot studies revealed that the use of a chemically defined medium not supplemented with foetal bovine serum generally reduced such tissue outgrowth, it was not completely absent in our explant model. Given that such tissue was not explicitly removed in this study, it may be that higher push-out forces observed in the chondrocyte seeded group are a result of greater tissue outgrowth associated with the higher levels of matrix accumulation by chondrocytes compared to MSCs. It is also possible that failure of the gel/tissue material itself, as apposed to the interface with the explant, contributes to the measured failure properties.The magnitudes of interface strength reported in this paper are of a similar magnitude to other reported studies. For example, the strength of the chondrocyte seeded group $(64 \mathrm{kPa})$ is higher than that reported by 
Hunter et al. $(\sim 10 \mathrm{kPa})$, but lower than that reported by Obradovic et al $(\sim 80-384$ $\mathrm{kPa}$ ) following bioreactor culture. Differences in species, culture conditions, testing regimes etc may explain much of the reported differences. For example, Dhert et al have demonstrated using finite element modelling that factors associated with the experimental set-up of push-out tests will influence the resulting interfaces stresses. ${ }^{12}$ Higher resolution imaging to access neo-tissue organisation at the interface should also be considered in future cartilage explant studies.

Matrix accumulation in both the MSC and chondrocyte seeded groups was inhibited by the presence of a surrounding cartilaginous ring, as evidenced by a significant decrease in GAG content in these groups compared to free swelling controls. Given that the diffusion coefficient of articular cartilage to key chondrogenic molecules is lower than that in free solution, ${ }^{28,34,53-55}$ it would seem reasonable to assume that diffusional limitations associated with the surrounding cartilage may be partially responsible for this result. Related to this is the possibility that the surrounding articular cartilage may be acting as a sink for such regulatory molecules, as various growth factors have been observed to bind to cell receptors and cartilage matrix components; ${ }^{47,48,60}$ most likely proteoglycans and/or some other noncollagenous matrix proteins. Matrix components may also neutralise the activity of growth factors. ${ }^{47}$ It is also unclear what role the physical confinement of the cartilage explant has on chondrogenesis. Confining self assembled tissue engineered cartilage for 2 weeks in agarose wells has been shown to increase the compressive stiffness of the construct without a change in the GAG or collagen content. ${ }^{13}$ However the growth dynamics of self-assembled cartilaginous tissues and those engineered in hydrogels are fundamentally different, leading to altered levels of physical stimuli acting on the developing tissues. This complicates comparisons between these two culture systems. 
It has also been suggested that soluble factors released from surrounding cartilage can inhibit cell proliferation and matrix accumulation in chondrocyte seeded hydrogels within such explant models. ${ }^{20}$ This inhibition was observed whether or not the cell seeded hydrogel was cultured inside a cartilage annuli, or in close proximity to the explant. ${ }^{20}$ Therefore the inhibition of MSC chondrogenesis observed in this study may also be due to the presence of such factors released by the surrounding cartilage tissue as nitric oxide, cathepsins or MMPs that are released and activated when the cartilage is damaged leading to cell death and tissue degradation. However there is also evidence to suggest that chondrogenesis of MSCs might be enhanced in the presence of viable cartilaginous tissue. For example, it has been demonstrated that chondrocytes can store latent pro-chondrogenic cytokines such as TGF- $\beta$, and can regulate both the temporal and spatial activation of such molecules. ${ }^{41}$ Co-culture of MSCs with chondrocyte-like cells has been proposed as a novel strategy to induce chondrogenic differentiation of MSCs. ${ }^{6,31,39,46}$ Co-culture of xenogenic MSCs and chondrocytes has revealed that while the presence of MSCs can enhance chondrogenesis of chondrocytes, a chondroinductive effect by chondrocytes on MSCs was not observed. ${ }^{56}$ Similarly, co-culture of MSCs with nucleus pulposus cells has been demonstrated to enhance chondrogenesis, ${ }^{46}$ but only if cell to cell contact is allowed, which is generally absent in the explant model employed in this study. Intimate contact between different cell types may lead to a more efficient transduction of molecular signals that induce chondrogenesis. Surface receptors of adjacent cells come into direct physical contact, and the autocrine and paracrine factors secreted by one cell type readily interact with the other. ${ }^{6}$ To completely de-couple these different possible effects, future studies will include controls where MSC seeded hydrogels are 
cultured in the proximity of cartilage explants, in media supplemented with and without known anabolic and catabolic cytokines.

The results of this explant study suggest that alterations to the biochemical or biophysical environment may be required before MSCs produce similar results to primary chondrocytes. In the future such models could also be improved by incorporating the many additional factors known to be present in the in vivo environment, but missing in this in vitro model, such as bone morphogenic proteins or fibroblast growth factor. Cartilage explant models can also be extended to include the subchondral bone, ${ }^{51}$ which among other benefits, may be a source of soluble factors (e.g. bone morphogenetic proteins) that regulate chondrogenesis in vivo. Another critical factor to include in future in vitro models of MSC based cartilage repair is physiological levels of mechanical loading to the explant, ${ }^{19}$ which has previously been demonstrated to regulate chondrogenesis of MSCs in various bioreactor systems. $^{10,17,38,52}$ Dynamic loading will also influence the transport of large molecules in such constructs. ${ }^{3,35}$ Cartilage treatments should also be investigated, as other authors have already shown in cartilage repair studies that treatment with highly purified collagenase and/or hyaluronidase improves integrative cartilage repair. ${ }^{7}$ Finally the use of alternative scaffold materials to agarose should be investigated (e.g. fibrin, collagen), as agarose does not allow for significant cell movement, limiting their ability to migrate to the cartilage interface. Inclusion of these and other factors will significantly improve in vitro models of cartilage repair, potentially reducing the need for animal model trials and providing controlled experiments prior to clinical investigations. 


\section{Acknowledgements}

Funding was provided by Science Foundation Ireland (President of Ireland Young Researcher Award - 08/YI5/B1336) 


\section{References}

1. Ahsan, T.; R. L. Sah. Biomechanics of integrative cartilage repair. Osteoarthritis and Cartilage 7(1):29-40; 1999.

2. Ait Si Selmi, T.; P. Neyret; P. C. M. Verdonk; L. Barnouin. Autologous chondrocyte transplantation in combination with an alginate-agarose based hydrogel (Cartipatch). Techniques in Knee Surgery 6(4):253-258; 2007.

3. Albro, M. B.; N. O. Chahine; R. Li; K. Yeager; C. T. Hung; G. A. Ateshian. Dynamic loading of deformable porous media can induce active solute transport. Journal of Biomechanics 41(15):3152-3157; 2008.

4. Awad, H. A.; M. Q. Wickham; H. A. Leddy; J. M. Gimble; F. Guilak. Chondrogenic differentiation of adipose-derived adult stem cells in agarose, alginate, and gelatin scaffolds. Biomaterials 25(16):3211-3222; 2004.

5. Barry, F.; R. E. Boynton; B. Liu; J. M. Murphy. Chondrogenic differentiation of mesenchymal stem cells from bone marrow: differentiation-dependent gene expression of matrix components. Exp Cell Res 268(2):189-200; 2001.

6. Boon, C. H.; T. Cao; H. L. Eng. Directing stem cell differentiation into the chondrogenic lineage in vitro. Stem Cells 22(7):1152-1167; 2004.

7. Bos, P. K.; J. DeGroot; M. Budde; J. A. Verhaar; G. J. van Osch. Specific enzymatic treatment of bovine and human articular cartilage: implications for integrative cartilage repair. Arthritis Rheum 46(4):976-985; 2002.

8. Brittberg, M.; A. Lindahl; A. Nilsson; C. Ohlsson; O. Isaksson; L. Peterson. Treatment of deep cartilage defects in the knee with autologous chondrocyte transplantation. New England Journal of Medicine 331(14):889-895; 1994.

9. Bruder, S. P.; N. Jaiswal; S. E. Haynesworth. Growth kinetics, self-renewal, and the osteogenic potential of purified human mesenchymal stem cells during 
extensive subcultivation and following cryopreservation. Journal of Cellular Biochemistry 64(2):278-294; 1997.

10. Campbell, J. J.; D. A. Lee; D. L. Bader. Dynamic compressive strain influences chondrogenic gene expression in human mesenchymal stem cells. Biorheology 43(3-4):455-470; 2006.

11. Caplan, A. I. Mesenchymal stem cells. Journal of Orthopaedic Research 9(5):641-650; 1991.

12. Dhert, W. J.; C. C. Verheyen; L. H. Braak; J. R. de Wijn; C. P. Klein; K. de Groot; P. M. Rozing. A finite element analysis of the push-out test: influence of test conditions. J Biomed Mater Res 26(1):119-130; 1992.

13. Elder, B. D.; K. A. Athanasiou. Effects of confinement on the mechanical properties of self-assembled articular cartilage constructs in the direction orthogonal to the confinement surface. J Orthop Res 26(2):238-246; 2008.

14. Erickson, I. E.; A. H. Huang; C. Chung; R. T. Li; J. A. Burdick; R. L. Mauck. Differential maturation and structure-function relationships in mesenchymal stem cell- and chondrocyte-seeded hydrogels. Tissue Eng Part A 15(5):1041$1052 ; 2009$.

15. Gratz, K. R.; V. W. Wong; A. C. Chen; L. A. Fortier; A. J. Nixon; R. L. Sah. Biomechanical assessment of tissue retrieved after in vivo cartilage defect repair: Tensile modulus of repair tissue and integration with host cartilage. Journal of Biomechanics 39(1):138-146; 2006.

16. Horas, U.; D. Pelinkovic; G. Herr; T. Aigner; R. Schnettler. Autologous chondrocyte implantation and osteochondral cylinder transplantation in cartilage repair of the knee joint. A prospective, comparative trial. Journal of Bone and Joint Surgery - Series A 85(2):185-192; 2003. 
17. Huang, C. Y. C.; K. L. Hagar; L. E. Frost; Y. Sun; H. S. Cheung. Effects of cyclic compressive loading on chondrogenesis of rabbit bone-marrow derived mesenchymal stem cells. Stem Cells 22(3):313-323; 2004.

18. Huang, C. Y. C.; P. M. Reuben; G. D'Ppolito; P. C. Schiller; H. S. Cheung. Chondrogenesis of Human Bone Marrow-Derived Mesenchymal Stem Cells in Agarose Culture. Anatomical Record - Part A Discoveries in Molecular, Cellular, and Evolutionary Biology 278(1):428-436; 2004.

19. Hunter, C. J.; M. E. Levenston. The influence of repair tissue maturation on the response to oscillatory compression in a cartilage defect repair model. Biorheology 39(1-2):79-88; 2002.

20. Hunter, C. J.; M. E. Levenston. Maturation and integration of tissueengineered cartilages within an in vitro defect repair model. Tissue Eng 10(56):736-746; 2004.

21. Ignat'eva, N. Y.; N. A. Danilov; S. V. Averkiev; M. V. Obrezkova; V. V. Lunin; E. N. Sobol. Determination of hydroxyproline in tissues and the evaluation of the collagen content of the tissues. J Anal Chem 62(1):51-57; 2007.

22. Johnson, T. S.; J. W. Xu; V. V. Zaporojan; J. M. Mesa; C. Weinand; M. A. Randolph; L. J. Bonassar; J. M. Winograd; M. J. Yaremchuk. Integrative repair of cartilage with articular and nonarticular chondrocytes. Tissue Engineering 10(9-10):1308-1315; 2004.

23. Johnstone, B.; T. M. Hering; A. I. Caplan; V. M. Goldberg; J. U. Yoo. In vitro chondrogenesis of bone marrow-derived mesenchymal progenitor cells. Experimental Cell Research 238(1):265-272; 1998. 
24. Kadiyala, S.; R. G. Young; M. A. Thiede; S. P. Bruder. Culture expanded canine mesenchymal stem cells possess osteochondrogenic potential in vivo and in vitro. Cell Transplantation 6(2):125-134; 1997.

25. Kafienah, W.; T. J. Sims. Biochemical methods for the analysis of tissueengineered cartilage. Methods Mol Biol 238:217-230; 2004.

26. Kim, Y. J.; R. L. Sah; J. Y. Doong; A. J. Grodzinsky. Fluorometric assay of DNA in cartilage explants using Hoechst 33258. Anal Biochem 174(1):168$176 ; 1988$.

27. Kuroda, R.; K. Ishida; T. Matsumoto; T. Akisue; H. Fujioka; K. Mizuno; H. Ohgushi; S. Wakitani; M. Kurosaka. Treatment of a full-thickness articular cartilage defect in the femoral condyle of an athlete with autologous bonemarrow stromal cells. Osteoarthritis and Cartilage 15(2):226-231; 2007.

28. Leddy, H. A.; F. Guilak. Site-specific molecular diffusion in articular cartilage measured using fluorescence recovery after photobleaching. Annals of Biomedical Engineering 31(7):753-760; 2003.

29. Lennon, D. P.; A. I. Caplan. Isolation of human marrow-derived mesenchymal stem cells. Exp Hematol 34(11):1604-1605; 2006.

30. Li, W. J.; R. Tuli; C. Okafor; A. Derfoul; K. G. Danielson; D. J. Hall; R. S. Tuan. A three-dimensional nanofibrous scaffold for cartilage tissue engineering using human mesenchymal stem cells. Biomaterials 26(6):599$609 ; 2005$.

31. Lu, Z. F.; B. Zandieh Doulabi; P. I. Wuisman; R. A. Bank; M. N. Helder. Differentiation of adipose stem cells by nucleus pulposus cells: Configuration effect. Biochemical and Biophysical Research Communications 359(4):991996; 2007. 
32. Maniatopoulos, C.; J. Sodek; A. H. Melcher. Bone formation in vitro by stromal cells obtained from bone marrow of young adult rats. Cell and Tissue Research 254(2):317-330; 1988.

33. Marcacci, M.; E. Kon; S. Zaffagnini; G. Filardo; M. Delcogliano; M. P. Neri; F. Iacono; A. P. Hollander. Arthroscopic second generation autologous chondrocyte implantation. Knee Surgery, Sports Traumatology, Arthroscopy 15(5):610-619; 2007.

34. Maroudas, A. Distribution and diffusion of solutes in articular cartilage. Biophysical Journal 10(5):365-379; 1970.

35. Mauck, R. L.; C. T. Hung; G. A. Ateshian. Modeling of Neutral Solute Transport in a Dynamically Loaded Porous Permeable Gel: Implications for Articular Cartilage Biosynthesis and Tissue Engineering. Journal of Biomechanical Engineering 125(5):602-614; 2003.

36. Mauck, R. L.; X. Yuan; R. S. Tuan. Chondrogenic differentiation and functional maturation of bovine mesenchymal stem cells in long-term agarose culture. Osteoarthritis Cartilage 14(2):179-189; 2006.

37. Moretti, M.; D. Wendt; D. Schaefer; M. Jakob; E. B. Hunziker; M. Heberer; I. Martin. Structural characterization and reliable biomechanical assessment of integrative cartilage repair. Journal of Biomechanics 38(9):1846-1854; 2005.

38. Mouw, J. K.; J. T. Connelly; C. G. Wilson; K. E. Michael; M. E. Levenston. Dynamic compression regulates the expression and synthesis of chondrocytespecific matrix molecules in bone marrow stromal cells. Stem Cells 25(3):655$663 ; 2007$.

39. Ni, Y. F.; X. F. Li; Y. Liu; Z. J. Lei; Q. Lu. In vivo chondrogenesis by coculture of rabbit bone marrow-derived mesenchymal stem cells and 
chondrocytes. Journal of Clinical Rehabilitative Tissue Engineering Research 12(16):3185-3188; 2008 .

40. Obradovic, B.; I. Martin; R. F. Padera; S. Treppo; L. E. Freed; G. VunjakNovakovic. Integration of engineered cartilage. J Orthop Res 19(6):10891097; 2001.

41. Pedrozo, H. A.; Z. Schwartz; R. Gomez; A. Ornoy; W. Xin-Sheng; S. L. Dallas; L. F. Bonewald; D. D. Dean; B. D. Boyan. Growth plate chondrocytes store latent transforming growth factor (TGF)- ?1 in their matrix through latent TGF-?1 binding protein-1. Journal of Cellular Physiology 177(2):343-354; 1998.

42. Pelttari, K.; E. Steck; W. Richter. The use of mesenchymal stem cells for chondrogenesis. Injury 39 Suppl 1:S58-65; 2008.

43. Peretti, G. M.; L. J. Bonassar; E. M. Caruso; M. A. Randolph; C. A. Trahan; D. J. Zaleske. Biomechanical analysis of a chondrocyte-based repair model of articular cartilage. Tissue Engineering 5(4):317-326; 1999.

44. Peterson, L.; T. Minas; M. Brittberg; A. Nilsson; E. Sjo?gren-Jansson; A. Lindahl. Two-to 9-year outcome after autologous chondrocyte transplantation of the knee. Clinical Orthopaedics and Related Research (374):212-234; 2000.

45. Pittenger, M. F.; A. M. Mackay; S. C. Beck; R. K. Jaiswal; R. Douglas; J. D. Mosca; M. A. Moorman; D. W. Simonetti; S. Craig; D. R. Marshak. Multilineage potential of adult human mesenchymal stem cells. Science 284(5411):143-147; 1999.

46. Richardson, S. M.; R. V. Walker; S. Parker; N. P. Rhodes; J. A. Hunt; A. J. Freemont; J. A. Hoyland. Intervertebral disc cell-mediated mesenchymal stem cell differentiation. Stem Cells 24(3):707-716; 2006. 
47. Ruoslahti, E.; Y. Yamaguchi. Proteoglycans as modulators of growth factor activities. Cell 64(5):867-869; 1991.

48. Schneiderman, R.; E. Snir; O. Popper; J. Hiss; H. Stein; A. Maroudas. Insulinlike growth factor-I and its complexes in normal human articular cartilage: Studies of partition and diffusion. Archives of Biochemistry and Biophysics 324(1):159-172; 1995.

49. Selmi, T. A. S.; P. Verdonk; P. Chambat; F. Dubrana; J. F. Potel; L. Barnouin; P. Neyret. Autologous chondrocyte implantation in a novel alginate-agarose hydrogel: Outcome at two years. Journal of Bone and Joint Surgery - Series B 90(5):597-604; 2008.

50. Silverman, R. P.; L. Bonasser; D. Passaretti; M. A. Randolph; M. J. Yaremchuk. Adhesion of tissue-engineered cartilage to native cartilage. Plastic and Reconstructive Surgery 105(4):1393-1398; 2000.

51. Tam, H. K.; A. Srivastava; C. W. Colwell Jr; D. D. D'Lima. In vitro model of full-thickness cartilage defect healing. Journal of Orthopaedic Research 25(9):1136-1144; 2007.

52. Thorpe, S. D.; C. T. Buckley; T. Vinardell; F. J. O'Brien; V. A. Campbell; D. J. Kelly. Dynamic compression can inhibit chondrogenesis of mesenchymal stem cells. Biochemical and Biophysical Research Communications; 2008.

53. Tognana, E.; F. Chen; R. F. Padera; H. A. Leddy; S. E. Christensen; F. Guilak; G. Vunjak-Novakovic; L. E. Freed. Adjacent tissues (cartilage, bone) affect the functional integration of engineered calf cartilage in vitro. Osteoarthritis and Cartilage 13(2):129-138; 2005.

54. Torzilli, P. A.; T. C. Adams; R. J. Mis. Transient solute diffusion in articular cartilage. Journal of Biomechanics 20(2):203-214; 1987. 
55. Torzilli, P. A.; J. M. Arduino; J. D. Gregory; M. Bansal. Effect of proteoglycan removal on solute mobility in articular cartilage. Journal of Biomechanics 30(9):895-902; 1997.

56. Tsuchiya, K.; G. Chen; T. Ushida; T. Matsuno; T. Tateishi. The effect of coculture of chondrocytes with mesenchymal stem cells on their cartilaginous phenotype in vitro. Materials Science and Engineering C 24(3):391-396; 2004.

57. Wakitani, S.; M. Nawata; K. Tensho; T. Okabe; H. Machida; H. Ohgushi. Repair of articular cartilage defects in the patello-femoral joint with autologous bone marrow mesenchymal cell transplantation: three case reports involving nine defects in five knees. Journal of tissue engineering and regenerative medicine 1(1):74-79; 2007.

58. Williams, C. G.; T. K. Kim; A. Taboas; A. Malik; P. Manson; J. Elisseeff. In vitro chondrogenesis of bone marrow-derived mesenchymal stem cells in a photopolymerizing hydrogel. Tissue Eng 9(4):679-688; 2003.

59. Worster, A. A.; B. D. Brower-Toland; L. A. Fortier; S. J. Bent; J. Williams; A. J. Nixon. Chondrocytic differentiation of mesenchymal stem cells sequentially exposed to transforming growth factor-?1 in monolayer and insulin-like growth factor-I in a three-dimensional matrix. Journal of Orthopaedic Research 19(4):738-749; 2001.

60. Yamaguchi, Y.; D. M. Mann; E. Ruoslahti. Negative regulation of transforming growth factor-? by the proteoglycan decorin. Nature 346(6281):281-284; 1990. 


\section{List of figures:}

\section{Figure 1:}

1.a. Diagram illustrating research design. A) Cartilage in cartilage. B) Agarose gels seeded with chondrocytes. C) Agarose gels seeded with MSCs. D) Cartilage annular rings filled with MSC seeded hydrogels. E) Cartilage annular rings filled with chondrocyte seeded hydrogels. 1.b. Diagram illustrating the injection method: Chondrocytes and MSCs were suspended in 2\% agarose at a density of 15 million cells/ml ( $\mathrm{n}=5$ per group). The solution was aspirated with a $1 \mathrm{ml}$ warm syringe and 18 gauge needle and injected into the cores created in the cartilage explants.

\section{Figure 2:}

Force-displacement curves for chondrocytes and MSCs seeded constructs. The peak force to push out the gel seeded with chondrocytes is higher than the force needed to push out the MSC seeded gel from the construct.

\section{Figure 3:}

A) Adipogenic potential of mesenchymal stem cells: colonies positive for oil red staining. B) Chondrogenic potential of mesenchymal stem cells: colonies staining positive for glycosaminoglycan with alcian blue (top image) and for collagen with picrosirius red (bottom image). C) Osteogenic potential of mesenchymal stem cells: colonies positive for alizarin red staining.

\section{Figure 4:}

Representative image of dead (ethidium bromide labelled; red) and live (calcein labelled; green) cells in MSC constructs after 48 hours. The live and dead cell population was more heterogeneously distributed in the agarose seeded gel when 
compared to the cartilage explant where non-viable, dead cells were predominantly situated near the cored cutting surface (original magnification $\mathrm{x} 100$ ).

\section{Figure 5:}

Microscopic appearance of cartilage explant and gel seeded with chondrocytes (first row), MSCs (second row) and cartilage (third row) at week 6. Sections taken from half-way through the depth of the construct were stained for Alcian Blue (stains glycosaminoglycan), picrosirius Red (stains collagen) and type II and I collagen by immunohistochemistry; original magnification x 100 .

\section{Figure 6:}

A: DNA content, B: GAG content and C: Total collagen content of MSC and chondrocyte explant core and free-swelling control gels at week $6 . * \mathrm{P}<0.05$. Typical DNA content in cartilage disks was $0.036 \% \mathrm{ww}$, GAG content was $5.3 \%$ ww and total collagen content was $8 \%$ ww. D: Failure stress during push-out testing for MSC and chondrocytes seeded constructs at week 6. * $p=0.0026$. 
Figure 1; Tatiana Vinardell

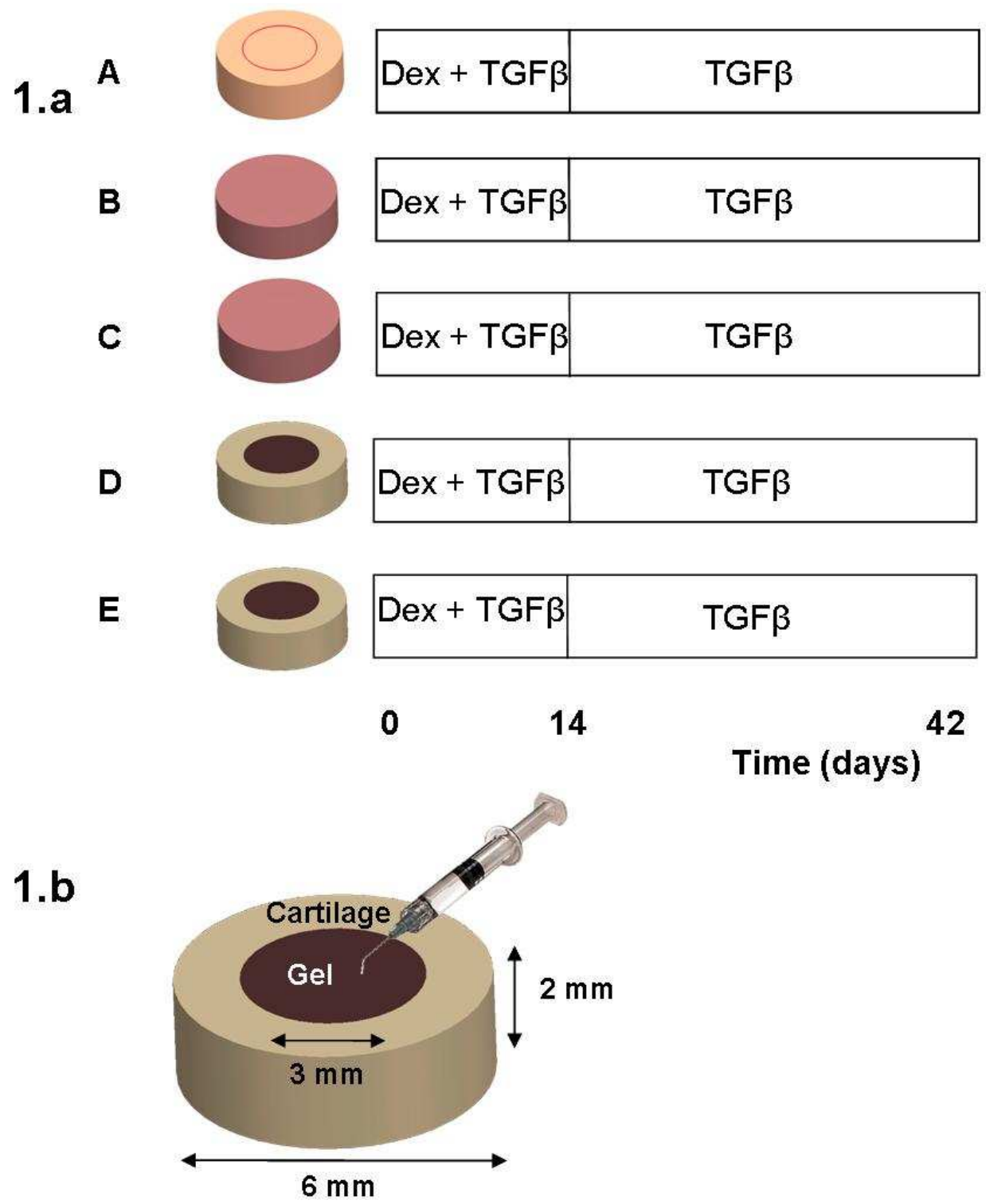


Figure 2; Tatiana Vinardell

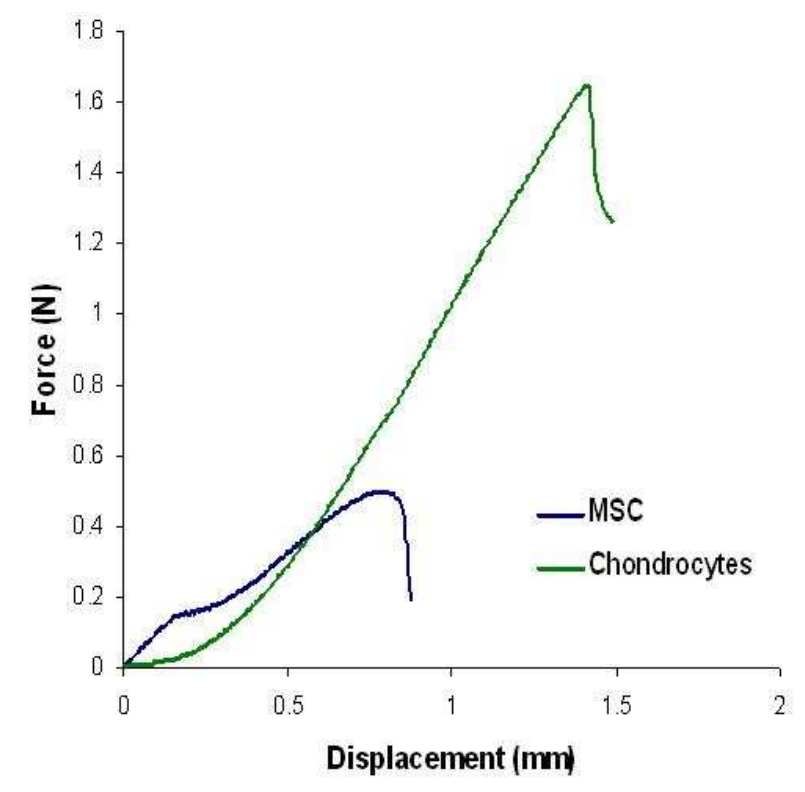

29

30

31

32

33

34

35

36

37

38

39

40

41

42

43

44

45

46

47

48

49

50

51

52

53

54

55

56

57

58

59

60

61

62

63 
Figure 3; Tatiana Vinardell

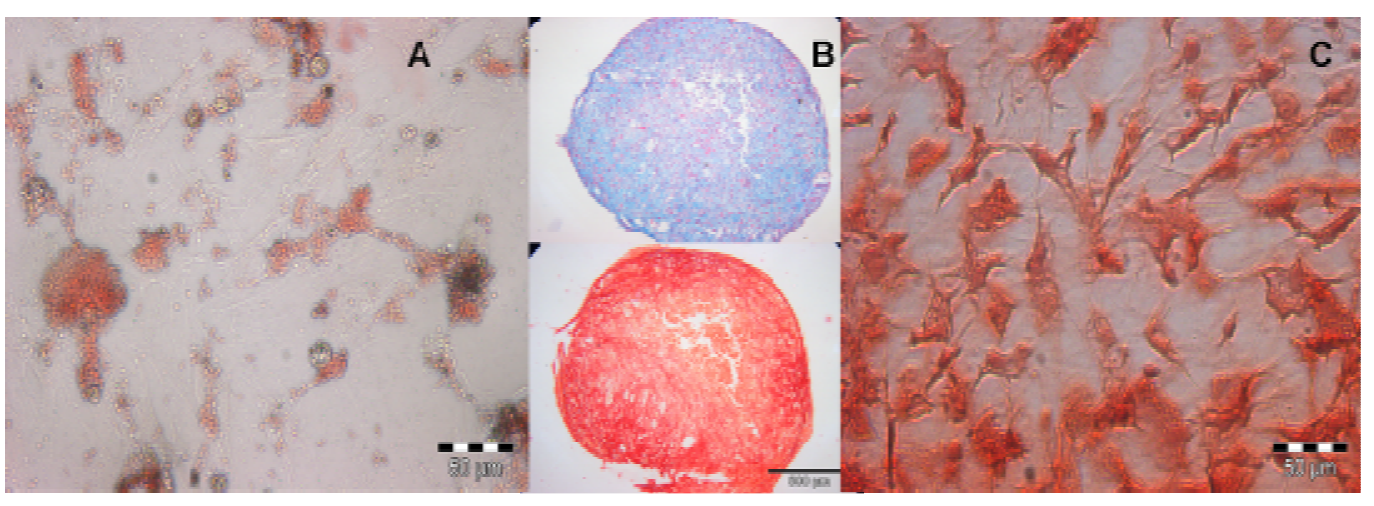

22

23

24

25

26

27

28

29

30

31

32

33

34

35

36

37

38

39

40

41

42

43

44

45

46

47

48

49

50

51

52

53

54

55

56

57

58

59

60

61

62

63 
Figure 4; Tatiana Vinardell

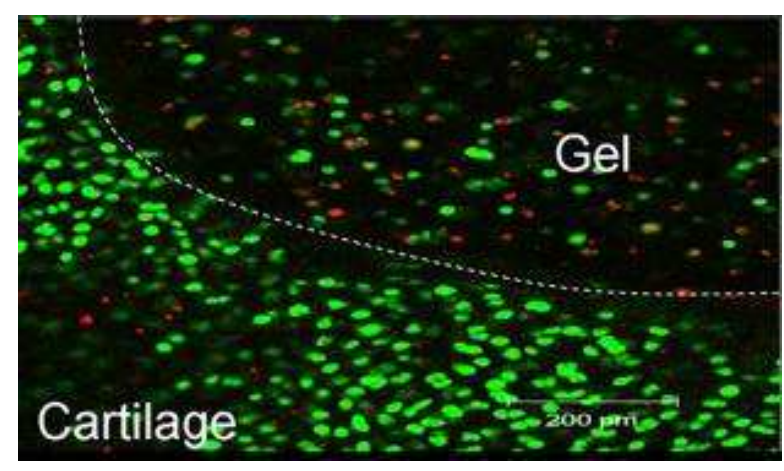


Figure 5; Tatiana Vinardell

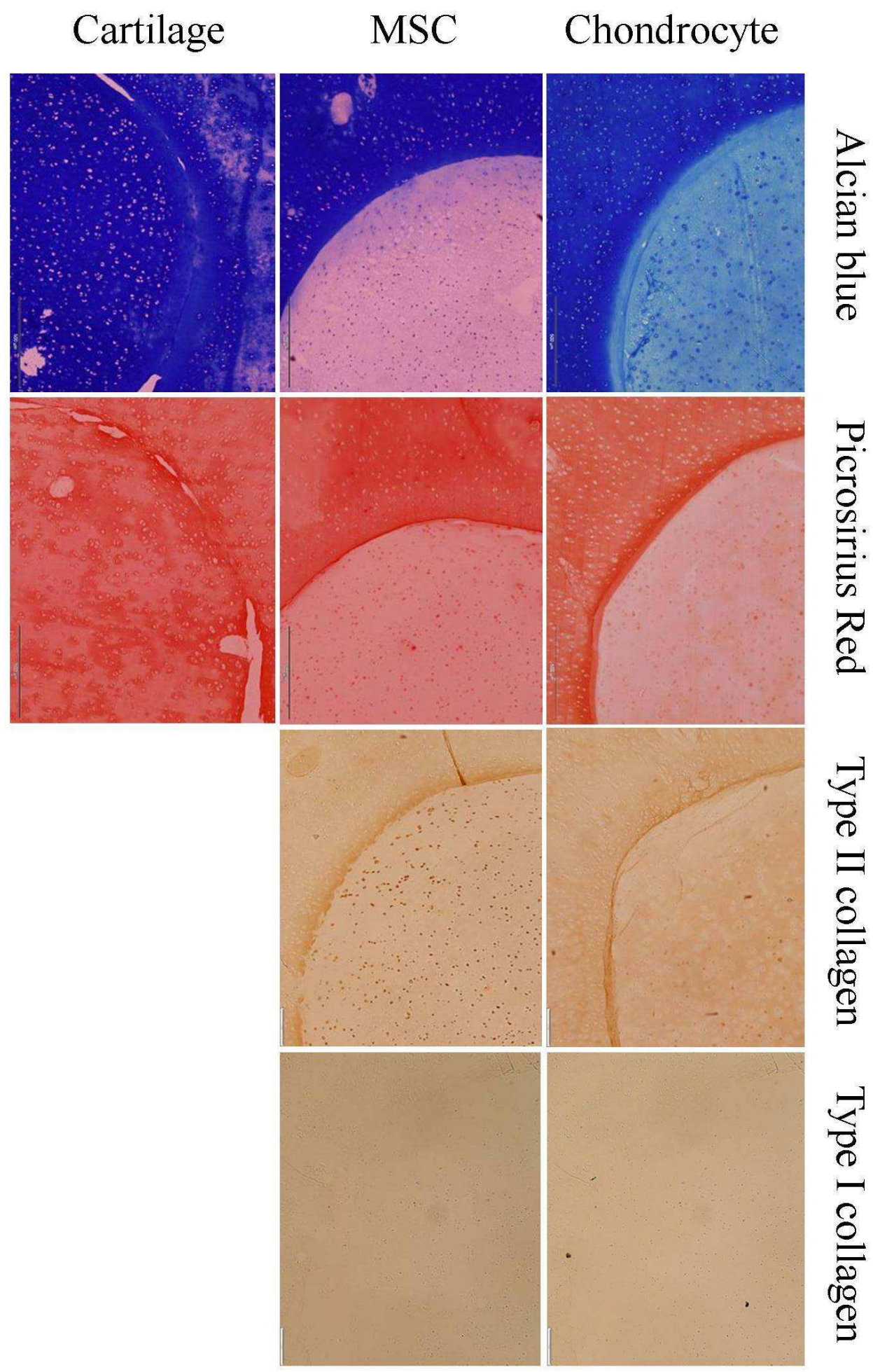

56

57

58

59

60

61

62 
Figure 6; Tatiana Vinardell

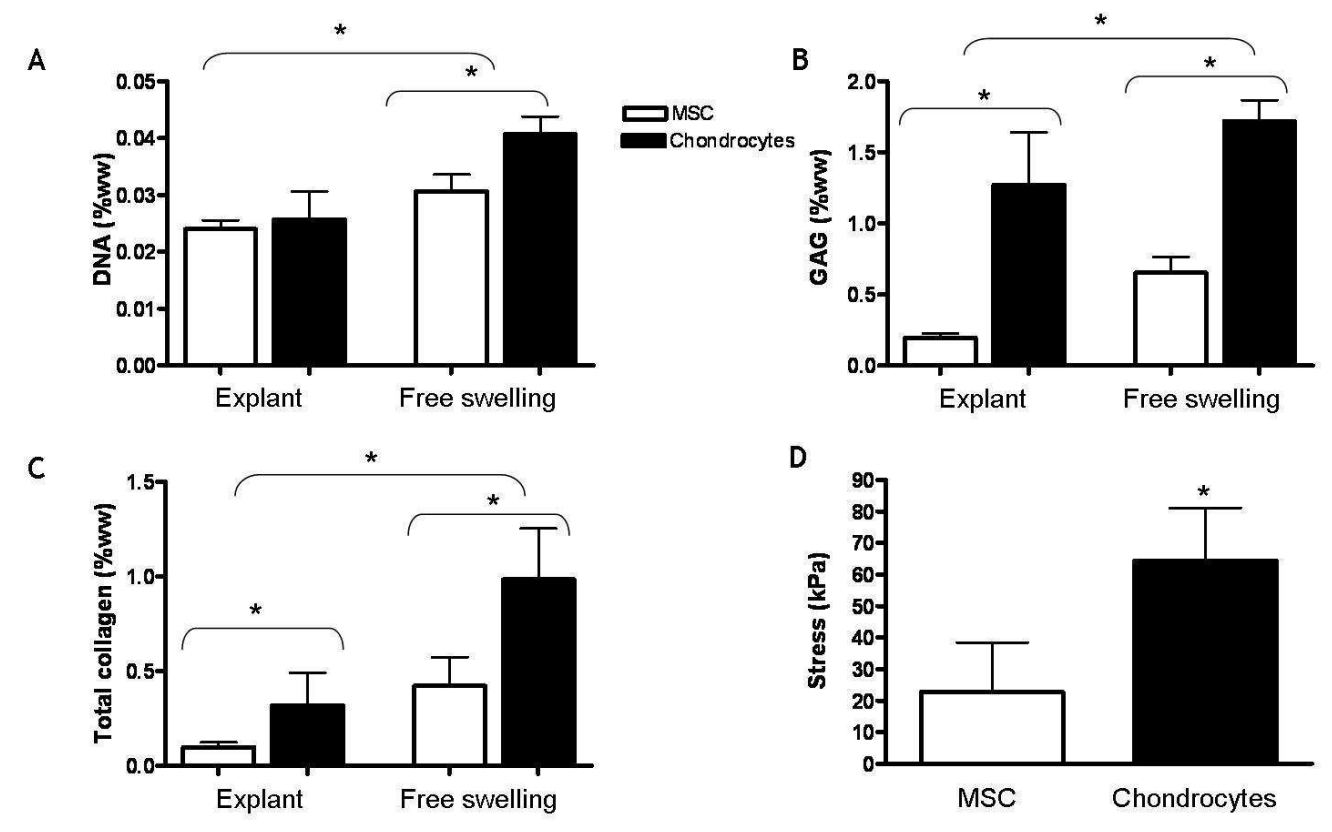

29

30

31

32

33

34

35

36

37

38

39

40

41

42

43

44

45

46

47

48

49

50

51

52

53

54

55

56

57

58

59

60

61

62

63 